\title{
Restoring grassy woodland diversity through direct seeding: insights from six 'best-practice' case studies in southern
}

\section{Australia}

Peter Cuneo, Paul Gibson-Roy, Graham Fifield, Linda Broadhurst, Tim Berryman, Andrew Crawford and David Freudenberger

\section{[Author contact block]}

Peter Cuneo is Manager Seedbank and Restoration Research with The Australian PlantBank, The Australian Botanic Garden, Mount Annan, Royal Botanic Gardens \& Domain Trust; Mount Annan NSW 2567, Australia Tel: +61 246347915; Email:

peter.cuneo@rbgsyd.nsw.gov.au). Paul Gibson-Roy is Lead Scientist with Greening Australia NSW (Building S9, Orchard Square, Western Sydney University, Bourke St, Richmond NSW 2753, Australia). Graham Fifield is Business Unit Leader with Greening Australia ACT (PO Box 538, Jamison, ACT 2614, Australia). Linda Broadhurst is Director with the Centre for Australian National Biodiversity Research (CSIRO National Research Collection GPO Box 1700, Canberra ACT 2601, Australia). Tim Berryman is Principal, Cumberland Plain Seeds (P.O. Box 201 Glenbrook, NSW 2773, Australia). Andrew Crawford is Research Scientist with the Department of Biodiversity, Conservation \& Attractions, Threatened Flora Seed Centre (Locked Bag 104, Bentley Delivery Centre, WA 6983, Australia). David Freudenberger is Senior Lecturer with Fenner School of Environment \& Society (Australian National University, Canberra ACT 0200, Australia.

Corresponding author.

This is the author manuscript accepted for publication and has undergone full peer review but has not been through the copyediting, typesetting, pagination and proofreading process, which may lead to differences between this version and the Version of Record. Please cite this article as doi: $10.1111 /$ emr.12315

This article is protected by copyright. All rights reserved 
Peter Cuneo. The Australian Botanic Garden, Mount Annan, Royal Botanic Gardens \& Domain Trust. Locked bag 6002, Mount Annan, NSW 2567. Email:

peter.cuneo@rbgsyd.nsw.gov.au Ph: 0246347915

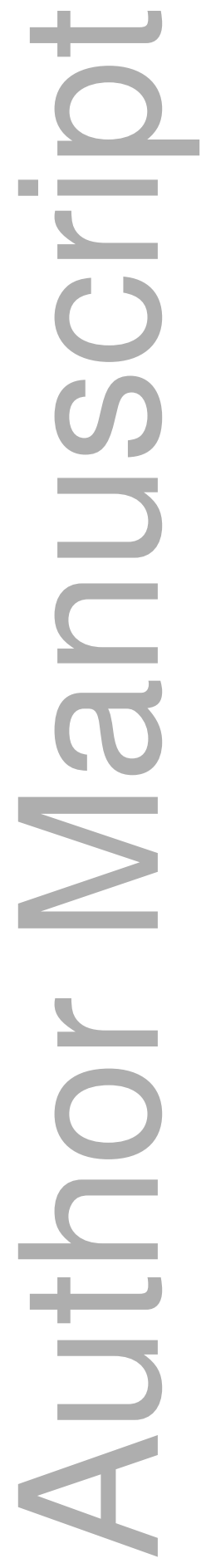


2 DR. PETER CUNEO (Orcid ID : 0000-0002-5217-370X)

3 DR. PAUL GIBSON-ROY (Orcid ID : 0000-0003-4794-911X)

4 DR. LINDA BROADHURST (Orcid ID : 0000-0002-9853-3328)

5 DR. DAVID FREUDENBERGER (Orcid ID : 0000-0002-3585-8600)

\section{Restoring grassy woodland diversity through direct seeding:}

\section{2 insights from six 'best-practice' case studies in southern}

\section{Australia}

Peter Cuneo, Paul Gibson-Roy, Graham Fifield, Linda Broadhurst, Tim Berryman, Andrew

17 Crawford and David Freudenberger

[Author contact block]

20 Peter Cuneo is Manager Seedbank and Restoration Research with The Australian PlantBank, The Australian Botanic Garden, Mount Annan, Royal Botanic Gardens \& Domain Trust; Mount Annan NSW 2567, Australia Tel: +61 246347915; Email: peter.cuneo@ rbgsyd.nsw.gov.au). Paul Gibson-

Roy is Lead Scientist with Greening Australia NSW (Building S9, Orchard Square, Western Sydney

24 University, Bourke St, Richmond NSW 2753, Australia). Graham Fifield is Business Unit Leader

25 with Greening Australia ACT (PO Box 538, Jamison, ACT 2614, Australia). Linda Broadhurst is

26 Director with the Centre for Australian National Biodiversity Research (CSIRO National Research

27 Collection GPO Box 1700, Canberra ACT 2601, Australia). Tim Berryman is Principal, Cumberland

28 Plain Seeds (P.O. Box 201 Glenbrook, NSW 2773, Australia). Andrew Crawford is Research

29 Scientist with the Department of Biodiversity, Conservation \& Attractions, Threatened Flora Seed

30 Centre (Locked Bag 104, Bentley Delivery Centre, WA 6983, Australia). David Freudenberger is 
31 Senior Lecturer with Fenner School of Environment \& Society (Australian National University,

32 Canberra ACT 0200, Australia.

34 [Intro block]

36 Ecological restoration of grassy woodland ecosystems is now a

37 significant landscape scale conservation objective throughout southern

38 Australia. Technological improvements in direct seeding of grassy

39 woodland species are now sufficiently well-advanced to examine

40 whether cost effective restoration of grassy woodlands is feasible.

41 Consideration of six 'best practice' case studies shows substantial

42 evidence of success. Further refinement of direct seeding techniques, in

43 combination with native seed production systems, however, will be

44 required into the future to meet the scale of woodland conservation targets and restore ecological function.

58 Woodland restoration has traditionally relied on labour intensive tree and shrub planting. However, 
60 combined with native seed production areas means that cost effective, landscape scale restoration of 61 grassy woodland diversity may now be possible in Australia. Here we draw on six projects 62 (presented at the National Seed Science forum in 2016) to seek insight into the factors important for 63 success, and consider any need for ongoing research to refine site preparation, seed delivery 64 techniques and field germination, particularly to increase species diversity and improve seed use 65 efficiency. Consideration is also given to implications of these case studies to the often-repeated call 66 for a sustainable and commercially viable native seed industry capable of providing large seed volumes (to agreed quality standards) to achieve restoration success across the many thousands of hectares where work is now required.

Since European settlement it is estimated that $47 \mathrm{M}$ ha of eucalypt woodland has been cleared across southern Australia (Booth et al. 2015), fragmenting many ecological communities (Prober et al. 2017). For example, some $10 \%$ of the federally-listed (Endangered) Box-Gum Grassy Woodlands ecological community is left in south eastern Australia, with almost half of this community occurring as small patches of less than 1 ha (Gibbons \& Boak, 2002; Prober \& Thiele 2005). This patchiness increases the vulnerability of this, and other plant communities to loss through natural attrition, changing land use, weed invasion and climate change. This creates a number of challenges for restoration practitioners, as they strive to fully restore these ecological communities. The challenges include the ability to source sufficient high quality seed from the diverse range of species required to achieve this goal, as well as being able to reliably germinate and efficiently use seed in restoration programs (Broadhurst et al 2015).

In the agricultural landscapes throughout southern Australia, much of the diverse native grassy and shrubby understorey components have been lost through extensive clearing, set stocking/livestock grazing, pasture improvement and the use of high phosphorus fertilisers and lime (Prober et al 2002). Loss of tree canopy combined with agricultural modification of soil nutrients, continues to provide a considerable challenge to restoration practitioners. Large scale direct seeding of trees and shrubs began in the 1990s during the 'decade of Landcare', although machinery capable of sowing seed from Australia's difficult grass and forb species was only developed as recently as 2010 (GibsonRoy et al. 2010). In the most recent review of direct seeding (Palma and Laurence 2015), forest ecosystems were most commonly the focus of restoration experiments, however this study of more than 120 papers worldwide noted that the selection of plant species in both forest and grassland ecosystems was significantly limited and potentially impaired by limited seed availability, biasing studies towards species producing frequent and abundant seed crops. 
95 In Australia, commercial seed collection is an important component of restoration programs for both 96 direct seeding and nursery tube-stock production. Despite the presence of a native seed industry in 97 Australia, the supply of quality native seed for broad scale ecological restoration remains a major 98 impediment. In the majority of projects, quantifiable seed quality data is not available or even 99 requested by seed users. This limits the purchaser's ability to ensure they are receiving value for 100 money, and to maximise the likelihood of success for their restoration projects. Considering the 101 complexity of ecosystems, it is regrettable that most restoration projects still only use a reduced set 102 of 10-20 key species, primarily eucalypts and acacias (Broadhurst et al. 2016). In an effort to 103 overcome seed supply issues, seed production areas are now beginning to be used to increase the 104 quantity and quality of a broader range of species, improving the species diversity available for 105 restoration projects and providing an alternative to unsustainable wild harvesting from small 106 remnants (Gibson-Roy et al. 2007). Compounding limited seed supply, is the inability of a 107 significant range of Australian native plants to persist with their exotic counterparts under conditions 108 of modified or 'improved' soil fertility. For this reason many practitioners continue to utilise this 109 limited set of key species where it is not feasible to modify soil conditions at the scale of the 110 revegetation project (10-100 ha).

113 The recently revised SERA National Standards for Ecological Restoration (Standards Reference 114 Group SERA 2017) provide a robust conceptual and practical framework for evaluating the recovery 115 of ecosystem attributes, and the types of interventions required for attaining outcomes modelled upon 116 appropriate reference ecosystems. Direct seeding is generally used to restore sites that are in the 117 more degraded National Restoration Standards category requiring 'reconstruction'. Importantly, the 118 case studies presented here frame the project approach and species used against a reference 119 ecosystem. This also provides an objective basis for assessing whether a trajectory towards the 120 reference system is being achieved.

122 [Insert Fig 1 somewhere here]

\section{Case studies}

126 Case study 1: Restoring Cumberland Plain grassy woodland understorey diversity at ha+ scale 127 in western Sydney 
129 Management body: Greening Australia

131 Ecological management issue: Native vegetation of the Cumberland Plain region in western Sydney

132 has been heavily cleared for agricultural purposes, and more recently for large scale urban

133 development. Techniques to restore degraded Cumberland Plain grassy woodland vegetation have

134 typically utilised tubestock plantings of primarily tree and shrub species into ex-pasture sites.

135 However, there has been limited success in restoring complex and diverse ground layer vegetation

136 using this approach (Nichols et al 2010).

138 Restoration objective and reference ecosystem: The goal of this three-year CFOC-funded project was 139 to reinstate 40 ha of diverse Cumberland Plain grassy woodland understorey through direct seeding 140 (Fig 1). Initiated in 2013, restoration sites were located in nine locations across the Cumberland 141 region of Western Sydney (Cranebrook Nature Reserve, Elizabeth MacArthur Reserve Camden, 142 Elizabeth Macquarie Reserve Windsor, Parrot Farm Reserve Narellan, Scheyville National Park, The 143 Ponds Schofields, Western Sydney Parklands, Western Sydney University Richmond, Wianamatta 144 Regional Park Ropes Crossing). At the projects' commencement all prospective seeding areas within 145 each of the nine restoration locations were dominated by exotic weeds (grassy at all but one where 146 African Olive dominated). The reference ecosystem used in planning restorations were local intact 147 examples of Cumberland Plain Woodland (where varying degrees of the original structure and 148 understorey diversity still existed). In general these remnants were linked to or situated near 149 restoration locations.

151 Methodology and seed technology: Methodology, including site preparation, was similar to the 152 Victorian sites described in Gibson-Roy et al. 2010) and which had been shown to be successful in 153 reinstating complex temperate lowland Australian ground layer vegetation. In this Sydney region 154 project, the seed resource (quantity and species diversity) required for reinstating a 40 ha area was 155 not locally available (i.e. via wild collection or though commercial suppliers). For this reason a seed 156 production program (with 5 ha footprint) was established to grow over 100 ground layer species 157 from the region. This facility utilized different types of growing systems (including in-ground seeded 158 grass crops and tubestock-planted, weed mat-covered wild flower beds) to cultivate the required 159 quantities of native seed. 
161 Initial preparation of restoration sites comprised herbicide treatments to remove weed biomass. At most sites this was followed by topsoil removal (to a depth of approximately 100mm) using earthmoving equipment. Where undertaken topsoil removal was used to lessen weed seed/bud loads and/or to lower site nutrient characteristics (primarily P and N) (Gibson-Roy and Delpratt 2015). Prepared sites (sprayed/soil-removed or sprayed) were then sown with a wide range of native ground layer species using a purpose-designed seeder which cultivated a friable sowing bed and delivered seed as a 'seed curtain' (rather than in drill lines). To gauge site success, sites were formally assessed over the program period using combinations of transect and randomised plot surveys to gather quantitative information on plant density - native/exotic, percentage vegetative cover - native/exotic, and species occurrence -native/exotic (Gibson-Roy, Greening Australia, 2018, unpublished data). Additional information came from field observations which we used to ascertain if impacts such as grazing pressure, vandalism and other forms of disturbances were negatively affecting sites and what

Outcomes and lessons learnt: Following site preparation and direct seeding the program successfully achieved the re-establishment of 40 ha of complex native ground layer vegetation on sites where exotic species had previously dominated - i.e. at most sites African Love Grass (Eragrostis curvula) and at one, the fiercely competitive woody African Olive (Olea europaea subsp. cuspidata). Native species establishment in the periods beyond 12 months post-seeding was routinely high with $70+\%$ of sown species recorded at all locations. Monitoring also revealed the presence of non-sown native species re-emerging within restorations adding further complexity and possibly resilience to the restoration sites. We surmise these were likely to have emerged from seed or bud banks or to have colonised from propagules supplied from nearby communities.

Monitoring from across the seven largest seeding locations revealed an average density of 41 native plants per $\mathrm{m}^{2}$ (a high of 51 plants per $\mathrm{m}^{2}$ and low of 23 plants per $\mathrm{m}^{2}$ ). These numbers represent considerably higher per hectare plant densities than are typically achieved by traditional herbaceous tubestock plantings. For example, 41 plants per $\mathrm{m}^{2}$ represents 410,000 plants per ha, while tubestock planting at a typical density of 6 plants per $\mathrm{m}^{2}$ (if established) would achieve 60,000 plants per ha. At these seeded densities it was also clear that the approaches used resulted in a wider range of species and functional types per unit area than would normally be planned for or achieved in 
195 Natural recruitment is often regarded as an important indicator of resilience rebuilding and so is a 196 key measure of restoration success (Standards Reference Group SERA 2017). Thus, an important observation captured in plot monitoring following establishment of reproductively mature vegetation was that seedling recruitment was occurring around established adults at all restoration sites (at higher levels than could be possibly be explained by previously ungerminated sown seed). For 200 example, at the largest single restoration (i.e. 10 ha Bungarribee precinct Western Sydney Parklands) 201 average native plant densities increased in one year by 24 plants per $\mathrm{m}^{2}$ (i.e. from the preceding years average of 26 per $\mathrm{m}^{2}$ to an average 50 per $\mathrm{m}^{2}$ ). Across this same site. percentage vegetative cover was represented by $32.5 \%$ native (29.4\% grass, $3.1 \%$ forb) and only $3.3 \%$ exotic $(2.6 \%$ grass, $0.7 \%$ forb). The remaining $64.2 \%$ was represented by inter-tussock gaps which are critical for plant recruitment. These restoration site characteristics were in stark contrast to the adjoining non-seeded vegetation (which represented the pre-seeding state) where vegetative cover was represented by $99.9 \%$ exotic and $0.1 \%$ native biomass.

210 With nine widespread restoration locations (and multiple seeding areas within four) some variation 211 in outcomes were expected. One example of this variation was the degree to which African 212 Lovegrass, a major regional weed, was controlled. Here monitoring revealed that where topsoil had 213 been removed on sites with heavier clay soils African Lovegrass suppression was more successful 214 than when it was removed (to similar depth) on sites with light sandy soils. For example, at one clay215 based location (Elizabeth MacArthur Reserve Camden) vegetative cover of ALG decreased post-soil 216 removal from $98 \%$ to $3.5 \%$, whereas at a sand-based location (Western Sydney University

217 Richmond) it decreased from $74 \%$ to $40 \%$ only (thus remaining a negative competitive factor for the 218 seeded natives and requiring substantial control inputs). A clear explanation for this outcome is not 219 known but we surmise may have something to do with deeper soil weed seedbanks in the lighter alluvial soils.

Another factor negatively impacting on the longer-term success at several restoration locations came from the influence of Eastern Grey Kangaroos (Macropus giganteus) and several studies have provided strong evidence of their negative impact on native plants (ACT Environment \& Planning 2015). We found that sites exposed to intense grazing by the Eastern Grey Kangaroo (i.e. national parks and reserves locations) were less successful in developing mature and/or reproductive vegetation which ultimately resulted in lower plant biomass, seed formation and subsequent seedling recruitment. Monitoring revealed this impact on vegetation cover between grazed and non-grazed 
229 sites. For example, percentage native vegetative cover at one heavily grazed location (Wianamatta 230 Nature Reserve) was only $>10 \% 18$ months after seeding, while at a non-grazed site (Elizabeth 231 MacArthur Reserve) it reached $70 \%$ after the same period. The management or exclusion of 232 macropods remains a contentious and potentially costly issue for both land managers and the wider 233 community. Due to such constraints, grazing at our sites is only likely to wane if currently unplanned 234 factors lessen this pressure. At sites where native establishment has been strong and macropod 235 grazing low or absent, the prime focus of longer term management has been on annual slashing to remove grass biomass and reinvigorate plants and where required, herbicide spraying (spot or wick wiping) to target problematic weeds such as African Love Grass, Purple Top (Verbena bonariensis)

241 [Insert Fig 2 somewhere here]

\section{Case study 2 : Grassy understorey restoration of highly degraded African olive forest sites}

Ecological management issue and vegetation condition: African Olive (Olea europaea subsp. cuspidata) is a highly invasive tree which forms a dense canopy (Cuneo \& Leishman 2006), outcompeting grassy woodland species that make up Cumberland Plain Woodland in south west Sydney. Control of dense African Olive stands on steep (previously cleared) hillsides and open woodland areas using mechanical mulching at the Australian Botanic Garden, Mount Annan, (ABGMA) produces heavy mulch cover followed by a profusion of annual weeds and African Olive seedling germination. The native soil seedbank has been largely depleted through long term suppression, with only scattered recruitment of hard-seeded native species from soil seedbank and grasses from adjacent intact vegetation sites. A key objective was to re-establish grassy understorey species as the first step in site stabilisation and restoration of a dense competitive grass layer resistant to African Olive invasion. Dense grass layer recruitment also aimed to provide a new source of propagules on degraded mechanically cleared sites. Species composition of the seed mix and the reference ecosystem was determined from a nearby high quality Cumberland Plain Woodland remnant with an intact grassy understorey. 
263 Methodology and seed technology: Nearby small patches of native grass had insufficient bulk seed 264 harvesting potential to supply seed for the 40 ha restoration site. A $1500 \mathrm{~m}^{2}$ grass seed production 265 area was thus developed for a secure seed supply. Seven local native perennial grass species (C3 and 266 C4) were grown in the seed production area, which produced a total output of $118 \mathrm{~kg}$ of seed 267 material in the first 2014/15 summer season. All seed batches were tested for germination at the 268 ABGMA Australian PlantBank facility which indicated an estimated total output of over 13 million 269 viable seeds from the first harvest season.

271 Due to the need for ongoing weed control and machinery access in 'transitional' areas where African 272 Olive was cleared, a decision was made to focus seeding efforts to a 5 hectare area and create $5 \mathrm{~km} \mathrm{x}$ $2732 \mathrm{~m}$ wide strips sown at high density (up to $3300 \mathrm{seeds} / \mathrm{m}^{2}$ ) (Fig. 2). Strips were spaced widely 274 enough to allow slashing access to adjacent areas. Seeded grass strips were prepared using a small 275 track machine with surface tilling attachment to provide good soil/seed contact. Seed material 276 (seed/stalks) were combined with compost and sand and hand broadcast (due to steep terrain) in 277 March 2015. The majority of seed material was provided by the seed production area, with some 278 additional species added from local wild-harvested collections.

280 Outcomes and lessons learnt: The combination of C3 and C4 grass species worked well, and 281 provided consistent germination throughout the cooler months (C3 grasses) and warmer months (C4 282 grasses). Weeping Meadow Grass (Microlaena stipoides) and Plume Grass (Dichelachne micrantha) 283 germinated strongly after good autumn rains, with established seedling recruitment densities of up to 284608 seedlings $/ \mathrm{m}^{2}$ recorded from monitoring plots after 10 months, showing that seed sowing rates 285 could be reduced with similar establishment densities achieved. The planted strips were not herbicide 286 treated prior to sowing, however surface tilling provided an acceptable level of broadleaf weed 287 control and good sown grass seed/soil contact. The primary focus on grasses also allowed the use of 288 broadleaf-selective herbicides after grass emergence. Plot monitoring after three years of 289 establishment, indicates that average native grass density was 48 plants/ $\mathrm{m}^{2}$ with 14 native grass 290 species recorded. Subsequent recruitment of short lived/high seed output summer grasses, e.g. 291 Windmill Grass (Chloris truncata) was also recorded. Larger clumping species such as Tussock 292 Grass (Poa labillardieri) and Kangaroo Grass (Themeda triandra) were more dominant after 3 years, 293 and significant grass thatch has accumulated. The dense sowing/strip technique and strong 294 recruitment proved to be a successful first step in restoration and providing an in situ 'nucleus' of 295 native grass propagules. Burning of grass strips could also provide niche opportunities for future 
296 sowing tree (e.g. eucalypt) and shrub (e.g. Fabaceae) species that could ultimately migrate outwards 297 from the nuclei along with the grasses.

300 [Insert Fig 3 somewhere here]

302 Case study 3 : large scale grassy ecosystem restoration at coal mine sites in the Hunter Valley, 303 NSW

Management body: Coal \& Allied Industries Limited.

Ecological management issue: In the Hunter Valley region, Coal \& Allied operate open-cut coal mines, and have been restoring assemblages of local native plant communities on 2100 ha of rehabilitated mined land since 2011, with the program expected to continue until the completion of mining. Although the sites were converted to agriculture prior to mining, the program is restoring

312 development, including Central Hunter Grey Box-Ironbark Woodland and Central Hunter Ironbark313 Spotted Gum Grey Box Forest. Both of these grassy woodland ecosystems are listed as Endangered 314 under State legislation and Critically Endangered under Federal legislation.

Methodology and seed technology: The project used a diverse seed mix incorporating 73 local native species, with a minimum of 14 tree, 24 shrub and 35 sub-shrub, forb and grass species sown at each site (Fig 3). Due to the scale of the project and large seed quantities required, there was some variation in the species used throughout the project, based on fluctuating seed availability. The project's seed supply was secured through collaborations with two restoration and seed supply contractors. The supply of native grass seed was a key component of the program, and was sourced as locally as possible from wild populations, including from several remnant native grasslands that have been actively managed for six years as local seed production paddocks. Grass seed harvested from over 500 ha of these paddocks, followed by processing and preparation of 4 tonnes of annual seed, requires significant contractor investment in seed handling/processing equipment. Final seed blends supplied by contractors included up to 20 species of native grass and 12 native forb species.

Direct seeding of treated areas was undertaken on a range of re-created soil profiles using material removed prior to mining operations. The common post-mining profile for direct seeding consists of 
357 [Insert Fig 4 somewhere here]

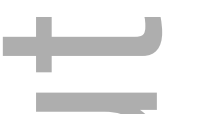
grassy woodland landscapes

mechanically shaped site topsoil underlain by subsoil/rock material that originally occurred above coal seams. In common with many direct seeding projects, the post-mining areas are highly disturbed with heavy weed seed loads and negligible natural regenerative capacity and native soil seedbank. Sowing occurred over more than six years on a large range of sites using techniques including drilling, hydroseeding and broadcasting. Seed application was undertaken in all seasons, with some taking place soon after earthworks were completed with minimal soil preparation, and others after significant time delays and extensive post soil placement and site preparation

Outcomes and lessons learnt: Plot and transect monitoring of vegetation establishment for the project, (as part of development consent conditions) recorded a total of 193 plant species, including 140 native species (73\%) and 53 exotic species (27\%) A total of 32 sites were monitored in relation to their performance against natural woodland reference sites. Complex restoration and habitat reconstruction takes time, and after an average of only 5 years since treatment many of the sites have met early benchmark criteria, and are now demonstrating infill native grass recruitment (J.Moen, Cumberland Plain Seeds, March 2017, pers. obs) indicating an acceptable trajectory given the age of the treated sites and difficult substrates. Variability in canopy species germination and establishment from direct seeding, can also lead to difficulties in meeting reference woodland benchmarks at restoration sites. For example, canopy tree establishment can range between $50-4,650$ stems/ha against a natural woodland target of 500 stems/ha. Throughout the project, a key factor in successful native species establishment is the use of relatively weed-free (ameliorated) subsoil/rock and topsoil, which reduces weed competition while native species are in the crucial establishment phase. Good rainfall soon after sowing triggers widespread germination and is a significant factor in establishment success. The priming (imbibition) of native seed during hydro-seeding may provide some benefits to germination and establishment when significant rainfall occurs soon after sowing, enabling natives to establish quickly and compete with the early influx of exotic plants.

Case study 4 : ‘Whole Of Paddock Rehabilitation' of native woody vegetation in agricultural

Management body: Greening Australia 
364 Ecological management issue: The Box-Gum Grassy Woodland belt sits within an agriculturally 365 productive zone of Australia extending from central Victoria to south-east Queensland. This 366 landscape has been economically prosperous for Australia, but this has come at considerable 367 environmental cost. Vast clearing and ongoing agricultural use has resulted in the loss of midstorey 368 shrubs, degradation of the diverse ground layer of grasses and forbs, as well as the removal and 369 subsequent lack of regeneration of keystone tree species such as eucalypts (Eucalyptus spp.). 370 Conservation, rehabilitation and landscape connectivity programs must therefore complement 371 agriculture - and be attractive to landholders - for meaningful and large scale outcomes to be realised 372 within this zone (Fifield 2016). This case study focuses on the re-establishment of tree and shrub 373 species on predominately simplified native pastures, within grazing properties in south-east NSW, 374 creating key habitat for a range of birds and mammals, as well as shade, shelter and improved 375 nutrition for livestock.

377 Methodology and seed technology: Historically, direct seeding in south east NSW has been used to 378 establish linear vegetation (windbreaks, wildlife corridors, riparian corridors) and to revegetate 379 unproductive land (eroded, saline, rocky etc.). These projects typically involve a very high cost of 380 additional fencing relative to the area revegetated. In the case of linear corridors the land is often 381 retired from production indefinitely, which understandably limits the area landholders are willing to 382 set aside.

384 In 2008, the Whole of Paddock Rehabilitation (WOPR) program offered a different approach to 385 direct seeding native woody vegetation, particularly for graziers or mixed farmers. This was 386 attained by incorporating trees and shrubs into the productive parts of the landscape (using existing 387 fencing) in such a way to complement rather than exclude agriculture (Fig 4). The resulting change 388 in scale of revegetation was substantial, with a typical project increasing from just 2 ha of fenced 389 corridors, to an average 20 ha paddock. The largest project to date is 100 ha. Trees and shrubs are 390 established in dense bands along the contour comprised of four rows, each spaced 4-5 m apart. Each 391 band is then separated by $40-50 \mathrm{~m}$ of pasture. This design, comprising approximately $25 \%$ canopy 392 cover, maximises shade and shelter for livestock, and habitat for insectivorous birds while 393 minimising competition between trees and pasture for light and moisture. Livestock are excluded 394 from the paddock (using the fencing already in place for grazing purposes) for 5 years only (the 395 period the trees and shrubs establish and grow beyond browsing height). During this time farmers are 396 partially compensated with stewardship payments provided through the program through state or 397 federal government grants. Only paddocks greater than 10 ha are considered for the program; thus 
critical patches of functional woodland habitat are being added to the agricultural matrix of linear strips, scattered individual trees, riparian corridors and remnant forests. The key difference is that we are not arguing over the size of the revegetation area as there is no net loss of land available for production after 5 years. All of which is proving attractive to farmers. The uptake of WOPR as of 2014 covered 80 paddocks and created 2012 ha of additional woodland habitat (Ansell et al. 2016).

Direct seeding is the primary technique used to establish trees and shrubs for WOPR. It is comparatively cheap, efficient and low risk. Tubestock planting is used for minor supplementation or under specific circumstances. Burford tree seeders towed with a four-wheel drive vehicle deliver seed within a $200 \mathrm{~mm}$ wide strip of cultivation. A GPS receiver is used in the vehicle to calculate the distance travelled and seeding rates. The typical seeding rate is $200 \mathrm{~g} / \mathrm{km}$, comprised of $150 \mathrm{~g}$ of fine seed (typically Myrtaceae) and $50 \mathrm{~g}$ of large seed (typically Fabaceae). These are sown through two separate seed boxes into different depths within the cultivated soil profile. This seeding rate results in approximately 30 fine seeds and 3 large seeds sown per metre. On average $700 \mathrm{~m}$ are sown per ha in cleared, open and arable WOPR paddocks.

Outcomes and lessons learnt: Because seed weights for eucalypts are highly variable, knowledge of the seed weights of individual species is important to predicting how many viable seeds are in the collections to be used for seeding. Seed weights and seed sizes for eucalypt species proportionally influence the likelihood of a species establishing from direct seeding. For example, when equal weights of Blakely's Red Gum (Eucalyptus blakelyi - 687 seeds per gram (Ralph 2003)) and Red Stringybark (E. macrorhyncha - 73-120 seeds per gram (Ralph 2003)) are sown together, Blakely's Red Gum has six to nine times more seed along the seeding lines, and thus greater chance of successful establishment. This has been confirmed by field surveys indicating significantly greater abundance of Blakely's Red Gum, and other species with a high number of seeds per gram, 2-19 years after seeding (Rayner 2010). The solution adopted has been to manipulate seed weights to ensure each species has the equivalent number of seeds being sown, based on the assumption that equal representation is desirable.

Field establishment rates for all eucalypts in WOPR sites sown between 2008 and 2012 were investigated by Adams-Schimminger et al (2017). The average density of eucalypt trees was 99/ha which represents approximately one stem every $7.5 \mathrm{~m}$ along each seeding line; a density that many farmers consider desirable. A density of 99/ha is also similar to the lower range (124- 228/ha) of small trees $(5-20 \mathrm{~cm}$ DBH) found in reference Yellow Box (E. melliodora) woodlands (Gibbons et al. 
432 2010). However, the mean value of 99 eucalypt trees/ha masks the striking variation in tree density 433 across WOPR paddocks of 15-370/ha. The variation is principally due to; very fine seeds being sown 434 on, or near, to the soil surface where moisture levels fluctuate wildly; the relatively slow growth and 435 establishment of eucalypts (when compared to species from Fabaceae); and the influence of weather 436 patterns such as La Nina and El Nino events on germination rates. This highlights the difficulty in 437 predicting the field establishment of fine-seeded eucalypts from direct seeding and further study into 438 methods to improve germination and establishment should be considered a priority.

440 What is the future of reconstructed WOPR sites? Following more than two decades of revegetation 441 we have observed that secondary recruitment (e.g. from seeds of plants previously grown by 442 tubestock or direct seeding) of trees and shrubs is governed by the same factors that affect 443 recruitment more broadly across the landscape. In the case of Eucalypt recruitment, Fischer et al 444 (2009) state that regular fertiliser application or continuous or near-continuous livestock grazing 445 prevents recruitment of seedlings. By proxy, Fabaceae species such as wattles, which are typically 446 higher in protein and more attractive to livestock are also being consumed shortly after germinating. 447 In our experience WOPR paddocks (and areas adjacent to linear corridors) which have been 448 managed under a rotational grazing regime and do not regularly receive fertiliser applications 449 similarly exhibit both Acacia and Eucalypt recruitment. Thus the future of reconstructed sites, 450 especially on agricultural land, will be dictated by the management actions made by individual land 451 holders.

Management body: Department of Biodiversity, Conservation and Attractions

459 Ecological management issue: Large quantities of native seed are required to meet the needs of the 460 restoration industry. Despite the size of the native seed industry and its capacity to supply seed for 461 small scale projects (e.g. local Landcare sites) through to large scale minesite restoration projects, 462 data on seed batch purity and viability is rarely available, and in most cases is not demanded by seed 463 customers. A recent study of native seed used in the Department of Biodiversity, Conservation and 464 Attractions' Banksia Woodland Restoration Project, a project aiming to restore Banksia woodland to 
465 degraded sites on the Swan Coastal Plain of Western Australia, provides a valuable insight into the native seed industry in that state and seed quality issues likely to be common across the whole sector.

Methodology and seed technology: Seed quality (measured as seed purity and seed viability) was determined for all collections supplied by four seed supply companies for the project. Seed purity was assessed by determining the percentage composition of intact seed units (ISTA 2012) by weight, in a seed collection as received from a seed supplier. In most instances inert matter such as broken plant material made up the remaining weight, with the presence of non-target species seed, including weed seed, being rare. Seed purity data was available for 635 seed collections (106 species, 50 genera, 18 families). Purity was generally high with $62 \%$ of collections having a purity $\geq 75 \%$. However $30 \%$ of collections had a purity $\leq 50 \%$. Whilst the purity of collections for some families such as Fabaceae and Proteaceae was often high, there were many exceptions. This was seen for Fabaceae collections where all but two of the 117 collections from the 12 genera tested had a purity $>75 \%$. For other families such as Myrtaceae, seed purity was highly variable among species as well

Viability of intact seed units was estimated using a germination test. Viability testing was completed for extracted seed only, and on species where reliable germination treatments have been established in scientific literature or experience with the relevant species or genus. Sample viability (germination) was assessed for 400 collections (62 species, 30 genera, 7 families) with germination of $\geq 75 \%$ obtained for $54 \%$ of the collections with $19 \%$ of the collections having germination of $\leq 50 \%$. Differences in seed viability were also observed within the same species, including seed batches sourced from an individual seed company. For example, Jarrah (Eucalyptus marginata) germination ranged from $1-81 \%$ across collections supplied by the same company. The combination of purity and sample germination enables the number of viable seed per gram to be estimated providing a standardised measure by which seed collections can be compared. For some species, the number of viable seeds per gram of sample could vary by orders of magnitude as illustrated by Sand Wattle Myrtle (Melaleuca thymoides). For this species the number of viable seed per gram ranged from 39 to 3700 . Interestingly, both these extreme values were from collections supplied by the same 
498 Outcomes and lessons learnt: The quality assessment of seed supplied for this restoration project indicated that although seed quality was often high, particularly for families such as Fabaceae, there were often exceptions. It is these exceptions that make generalising about seed quality problematic, and emphasise the importance of seed quality testing. Knowing the viability of seed prior to planting is of vital importance to ensure desired seeding rates are achieved. The implications of this study are that restoration projects using the same volume of seed from the best and worst collections of a given species would have dramatically different outcomes but this outcome, and the reason for it, would not necessarily be apparent to the project managers.

Case study 6 : Evaluating genetic diversity of two woody species in Seed Production Areas in the Goulburn Broken CMA

Ecological management issue and vegetation condition: Using poor quality seed can impact on restoration efforts if seed fails to thrive or if there is insufficient genetic diversity to help restored populations adapt to environmental change.

The fact that a high proportion of Federally-listed Box-Gum Grassy Woodlands occur as small patches of less than 1 ha (Gibbons and Boak 2002; Prober et al. 2002) has substantial implications for the genetic fitness of populations of plant species in remnants. Species with small and patchy distributions are known to be vulnerable to a range of threats including inbreeding. This creates challenges for collecting adequate amounts of high quality seed from nearby remnants, challenges that are starting to be addressed by the use of Seed Production Areas.

SPAs have been used by the forestry industry for decades to consistently produce high quality seed of known genetic quality for key species such as eucalypts and acacias but are rarely used for broadscale revegetation species in Australia. Given the costs associated with establishing and managing seed production areas, assessing the genetic diversity of stock plants and their seed crops is vital to ensure that high quality seed is being produced for restoration programs.

Methodology and seed technology: Established seed production area plants and associated seed crops for two key woodland revegetation species in Victoria, Mallee Wattle (Acacia montana) and Wedgeleaf Hopbush (Dodonaea viscosa subsp. cuneata), were compared genetically with source or nearby remnant populations. This provided an opportunity to determine whether natural levels of genetic 
532 diversity were held in the seed production areas, and were therefore being reintroduced back into 533 field restoration sites. It also provided an opportunity to assess levels of inbreeding and whether the 534 seed production areas were broadly representative of the natural populations.

536 Outcomes and lessons learnt: Levels of genetic diversity were comparable between the Seed 537 Production Areas at Numurkah and Dookie and natural populations (Broadhurst et al. 2017). 538 However, significant inbreeding was observed in many remnants and their associated seed crops - as 539 well as some seed production areas and the seed crops that these were producing. Seed production 540 areas were also biased towards the genetic profile of 1-2 remnants rather than representative of the 541 diversity originally planted. This study has highlighted the importance of careful selection of source 542 germplasm, and the necessity of tracking plant survival through the seed production area 543 establishment phase to ensure that broad genetic representation in maintained.

\section{Discussion}

These six case studies provide an insight into the evolving approaches and techniques being developed, trialled and applied to support ecological restoration across Australia. Not surprisingly, each project has a different aim, and has been implemented in an area with a different land-use history, across different scales and using variable budgets. Despite these differences, several consistent themes regarding use of direct seeding for Australian restoration are evident including:

Importantly, the case studies illustrate that direct seeding is an ever-evolving and multi-faceted exercise, that needs to consider the inability of native vegetation to supply seed especially into the future (Mortlock 2000; Broadhurst et al. 2016). In order to meet the ambitious landscape scale restoration goals now required for grassy woodlands, a sustainable and commercially viable native seed industry, with supply augmented by seed production areas is essential. Case study 5 identified some current quality and supply issues with the native seed industry, which could be addressed with 
565 Association of Western Australia (RIAWA) code provides the basis for a national code of practice to 566 be developed. Other RIAWA initiatives include Seed Industry Standards (RIAWA 2015) and a seed viability database for member use. Seed quality certification would also assist restoration practitioners, and provide an important germination baseline for direct seeding efforts, however, the high cost of laboratory standard germination testing remains a significant barrier to seed suppliers and clients.

The success of several case studies relied on highly managed seed production areas to overcome seed supply limitations, and deliver in-field germination and establishment. Grasses, in most cases have been the backbone of seed production where they occur, as these are highly responsive under cultivation, produce high seed output per plant and provide recruitment potential for restoration sites. Seed production areas are increasingly being used for native herbaceous species (forbs), but relatively few have been established for longer lived woody species. From overseas examples (Gibson-Roy 2015) and increasingly from local experience, it is becoming clear that seed production (including for important and/or rare species) is a critical technology for restoration seed supply if we are to achieve landscape scale change. However, attention to the genetic quality of seed, and strategies to ensure broad genetic representation within and between species, will be essential. A key goal for many practitioners is that restored sites become an additional seed source to meet the ever increasing demand for future projects. Therefore, documenting the provenance and genetic representativeness of seed sources are of critical importance.

A major focus evident in some of these case studies is the restoration of understorey diversity. This element is often the most vulnerable component of plant communities to threatening processes such as weed invasion and nutrient changes through fertiliser application (Prober et al. 2002). Although a range of approaches is used in woodland restoration including shading out understorey with woody species; for highly degraded sites where ground layer diversity is important, there appears to be considerable merit in a 'bottom up' approach (Cuneo and Leishman 2015, Gibson-Roy et al 2010). Such an approach relies on the dominant use of native grasses and forbs as the first stage of direct seeding, followed by the introduction of woody species. The strong establishment of a competitive native grass cover provides initial soil stability and a level of competition against weed invasion.

While direct seeding may be a lower cost method of getting plants in the ground, reconstruction of ground layer species diversity in high degradation cases using the methods of case study 1 requires a 
somewhat higher initial cost per unit area to create the low weed conditions necessary for long-term persistence. Due to the complexity and diversity in the ground layer of grassy woodland vegetation, such investment has demonstrated its value in terms of the number (greater than 100 species) of grasses and forbs that established. Case studies 2 and 3 provide further examples of opportunities to reconstruct native grassy woodland vegetation following woody weed invasion or mining operations, with varying costs and positive outcomes for biodiversity. Whole of paddock restoration (case study 4) illustrated an approach delivering a relatively simple suite of trees and shrubs ( $\leq 15$ species) across vast swathes of agricultural land for woodland bird and mammal habitat, but with the benefit of a lower cost per unit area. Ongoing weed management of direct seeded sites remains a key challenge, particularly when the aim is to restore a self-sustaining herbaceous ground layer. The use of highly selective soil-active herbicides as used in the agricultural sector, e.g. rice cropping (Taylor 2013), also offers opportunities to improve native plant germination and establishment through reduced weed competition. All of the case studies, however, highlight the need for a reliable supply of high quality seed, and the importance of effective site preparation, efficient seed delivery and reliable field germination/establishment.

Another significant field establishment issue identified in this, and other studies (Li et al. 2003) is the use of fine seeded species in direct seeding. The restoration of grassy woodland vegetation is not complete without establishment of the main tree canopy species, which are predominantly eucalypts. Eucalypts and most related Myrtaceae species are fine seeded, short distance dispersal plants (Brooker and Kleinig 1999) which require high volumes of seed in direct seeding projects, as outlined in case study 4. In comparison to larger seeded species (e.g. Fabaceae and Proteaceae), Myrtaceae species have a lower establishment rate (Hallett et al. 2011) in direct seeded projects, and are very prone to ant predation ( $\mathrm{Li}$ et al. 2003). Experience in West Australian mallee and woodland ecosystems with fine seeded Myrtaceae (Woodall 2010) led to the recommendations that seed be treated (primed) with ethylene, and the addition of nitrogen to low nutrient sandy soils for quicker eucalypt seedling establishment. In a study of direct seeded sites in south east NSW Rayner (2010) highlighted the dominance of particular eucalypt species, and the consistent absence or low numbers of others when equal seed weights were used. This study identified that when the seed characteristics are considered for each species, it is evident that the number of seeds applied to the soil surface, rather than the size of those seeds, had the greatest effect on the chance of establishment. We recommend that eucalypt sowing rates for multi-species projects thus be calibrated according to species weight and on known viability, to improve the predictability of germination and 
633 establishment. Given the significance of eucalypts in these restoration efforts, we suggest that fine

634 seeded species should be a key research area for future direct seeding research, as we seek to 635 maximise field germination of eucalypts through improved seed delivery, creation of microsites and 636 management of ant predation.

638 The restoration case studies presented demonstrate plant establishment and recruitment success 639 achieved in highly degraded ecosystems. These examples of the adaptive use of direct seeding 640 technology in ecosystem reconstruction, indicate that industry and practitioner experience exists in 641 Australia to tackle the challenge of reconstructing grassy woodland ecosystems, and that the 642 solutions identified to date could be more broadly adopted. Restoration and establishment of a wide 643 range of grassy woodland species using direct seeding, has been achieved at costs which are 644 significantly lower than using traditional tubestock planting and maintenance. Given the current 645 conservation status and degraded state of grassy woodlands throughout eastern Australia, a greater 646 level of long term political commitment to landscape scale conservation and restoration targets is 647 now required in order to sustain viable restoration and native seed industries. A large scale native 648 seed industry model that exists in the USA provides some useful concepts (Gibson-Roy 2015). Of 649 particular relevance to Australia are government incentives for farm-based biodiversity restoration 650 on private land, and the reinstatement of native vegetation along road corridors. Despite an 651 increasingly successful level of ecological restoration capability developing across Australia, as 652 evident in the case studies presented; we still lack the markets for restoration that would drive the 653 operational scales required to meet the restoration and conservation targets required to achieve 654 ecological functionality across the landscape.

\section{Acknowledgements}

659 We thank the Australian Seed Bank Partnership and organising committee of the National Seed 660 Science Forum, which was held at the Australian Botanic Garden, Mount Annan, NSW, 14-16 661 March 2016. Case study 1 was funded by a Federal Government, Caring For Our Country (CFOC) 662 grant number A00000 10710 G. Paul Gibson-Roy received a Churchill Scholarship to study native 663 seed production and biodiversity restoration in the U.S.A. We would like to acknowledge the 664 contributions of two anonymous reviewers which greatly improved the manuscript.

\section{References}

This article is protected by copyright. All rights reserved 
668 Adams-Schimminger M, Fifield G, Doran B, Freudenberger D (2017) Woodland rehabilitation

669 and biodiversity conservation in an agricultural landscape in south eastern Australia. Case

670 studies in the environment. University of California Press.

672 ACT Environment \& Planning (2015) ACT conservation research: the effects of kangaroo grazing 673 on biodiversity. ACT Government. Environment and Planning.

674 https://www.environment.act.gov.au/_data/assets/pdf_file/0007/902446/Effects-of-kangaroo-

675 grazing-and-biodiversity.pdf

Ansell D, Fifield G, Munro N, Freudenberger D, Gibbons P (2016) Softening the agricultural

matrix: a novel agri-environment scheme that balances habitat restoration and livestock

679 grazing. Restoration Ecology 24, 159-164.

Booth T., Broadhurst L., Pinkard L., Prober S., Dillon S., Bush D., Pinyopusarerk K., Doran J.,

Ivkovich M. and Young A. (2015) Native forests and climate change: lessons from eucalypts. Forest

Ecology and Management 347, 18-29.

Broadhurst L., Hopley T., Li L. and Begley J. (2017) A genetic assessment of seed production areas

(SPAs) for restoration. Conservation Genetics 18, 1257-1266.

Broadhurst L, Driver M, Guja L, North T, Vanzella B, Fifield G, Bruce S, Taylor D and Bush D.

(2015) Seeding the future - the issues of supply and demand in restoration in Australia. Ecological

Management \& Restoration 16, 29-32.

Brooker MIH, Kleinig DA, (1999) Field Guide to Eucalypts, Volume 1 (Bloomings Books:

Cuneo P, Leishman MR (2006) African Olive (Olea europaea subsp. cuspidata) as an

environmental weed in eastern Australia: a review. Cunninghamia 9, 545-577. 
701 Cuneo P, Leishman MR (2015) Recovery after African Olive invasion: can a 'bottom-up' approach to ecological restoration work? Ecological Management \& Restoration 16, 33-40.

Fifield G (2016) Working effectively with farmers on agri-environment investment. In

Fischer J, Stott J, Zerger A,Warren G, Sherren K, Forrester RI, (2009) Reversing a tree regeneration crisis in an endangered ecoregion. Proceedings of the National Academy of Sciences Jun 2009, 106 (25) 10386-10391; DOI: 10.1073/pnas.0900110106

Gibbons P, Briggs SV, Murphy DY, Lindenmayer DB, McElhinny C, Brookhouse M (2010)

Benchmark stem densities for forests and woodlands in south-eastern Australia under conditions of relatively little modification by humans since European settlement. Forest Ecology and Management 260, 2125-2133.

Gibson-Roy P, Delpratt J (2015) The Restoration of Native Grasslands In 'Land of Sweeping

732 Gibson-Roy, P. (2015) Investigating techniques for producing species-rich native seed crops for 733 biodiversity restoration. Churchill Fellowship Report

734 https://www.churchilltrust.com.au/media/fellows/Gibson_Roy_P_2015 
737 Hallett LM, Standish RJ, Hobbs RJ (2011) Seed mass and summer drought survival in a 738 Mediterranean-climate ecosystem. Plant Ecology 212, 1479-1489.

740 International Seed Testing Association (2012) ISTA Seed Testing Manual (International Seed 741 Testing Association: Basssersdorf, Switzerland)

744 Li J, Duggin JA, Grant CD, Loneragan WA (2003) Germination and early survival of 745 Eucalyptus blakelyi in grasslands of the New England Tablelands, NSW, Australia. Forest 746 Ecology and Management 173, 319-334.

748 Mortlock W (2000) Local seed for revegetation: Where will all that seed come from?

749 Ecological Management and Restoration 1, 93-101.

751 Nichols PWB, Morris EC, Keith DA (2010) Testing a facilitation model for ecosystem 752 restoration: does tree planting restore ground layer species in a grassy woodland? Austral 753 Ecology 35, 888-897.

Palma AC, Laurence SGW (2015) A review of the use of direct seeding and seedling

756 plantings in restoration: what do we know and where should we go? Applied Vegetation

Science $18,561-568$.

Prober SM, Gosper CR, Gilfedder L, Harwood TD, Thiele KR, Williams KJ, Yates CJ (2017)

760 Temperate Eucalypt Woodlands. In: Keith D. (ed.) Australian Vegetation, 3rd Edition. Cambridge 761 University Press

Prober SM, Thiele KR, Lunt ID (2002) Identifying ecological barriers to restoration in temperate grassy woodlands: soil changes associated with different degradation states.

Australian Journal of Botany 50, 699-712.

Prober SM, Thiele KR (2005) Restoring Australia's temperate grasslands and grassy woodlands: integrating function and diversity. Ecological Management and Restoration 6, 16-27. 
770 Ralph M (2003) 'Growing Australian native plants from seed : for revegetation, tree planting and direct seeding.'(Bushland Horticulture: Fitzroy Vic.)

Rayner I. (2010) Are direct seeded revegetation sites self-sustaining? An analysis of structure, composition and regeneration processes. Honours thesis, Fenner School of Environment and

Revegetation Industry Association of Western Australia (2015) Seed Industry Standards

http://riawa.com.au/wordpress/wp-content/uploads/2015/05/01-RIAWA-Seed-Standards-

1505201.pdf

Standards Reference Group SERA (2017) National Standards for the Practice of Ecological

Restoration in Australia. Second Edition. Society for Ecological Restoration Australasia. Available from URL: www.seraustralasia.com (accessed $25^{\text {th }}$ February 2017)

Taylor M, (2013) Weed control in aerobic rice to increase water use efficiency, Rural Industries

Research and Development Corporation, RIRDC Publication No 13/017.

Woodall GS, (2010) Improving the Direct Sowing of Commercial Native Plants in Agricultural

Lands of Southern Australia, Rural Industries Research and Development Corporation, RIRDC

Publication No 10/061.

\section{FIGURE CAPTIONS}

Figure 1. (a) Case Study 1's Narellan site after trittering to remove dense stands of African Olive followed by top soil removal to reduce weed seed loads. Different parts of the site were sown with

(b) native grasses or (c) native forbs to enable differential weed management with selective herbicides. Seed of over 100 species was produced in (d) the project's 5ha Seed Production Area. Viable seed mixtures were sown on friable seed beds at all nine sites after topsoil removal that restricted pre-existing pasture grasses or woody weeds. This resulted in reinstatement of 40 ha of 
803 Figure 2. (a) Case Study 2's removal of dense African Olive at the Australian Botanic Garden,

804 Mount Annan was followed by surface tilling and sowing of native grass seed in strips along the 805 contour as a first step in stabilisation and restoration of a dense competitive grass layer resistant to 806 African Olive invasion. (b) Windmill Grass and Plume Grass produced in the project's Seed 807 Production Area. (c) Dense germination of native grasses in the strips followed by the use of 808 broadleaf-selective herbicides has allowed the strips to become a new source of seed for outward 809 expansion over time. (Photos Peter Cuneo)

811 Figure 3. (a) Case Study 3's direct-seeding at a Coal and Allied minesite in the Hunter Valley NSW 812 after extensive site preparation; including weed control and soil amelioration. (b) Results of direct813 seeding of a woodland community in early establishment. Seed of the local native grasses and forbs 814 have been sourced from areas including local native grasslands actively managed for six years as 815 seed production paddocks. (Photos Tim Berryman)

817 Figure 4. Case Study 4's Whole of Paddock Rehabilitation (WOPR) program. (a) A project site 818 near Cootamundra NSW prior to sowing and (b) after sowing of trees and shrubs in bands along the 819 contour. This approach allows ongoing grazing while maximizing shade and shelter for livestock 820 and habitat for insectivorous birds. Livestock are excluded from the paddock (using the fencing 821 already in place for grazing purposes) for 5 years only during which time farmers are partially 822 compensated with stewardship payments administered by Greening Australia through state or federal 823 government grants. (Photos Greening Australia)

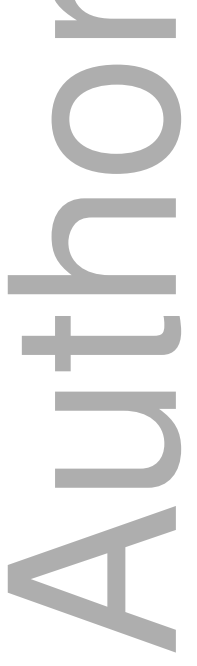



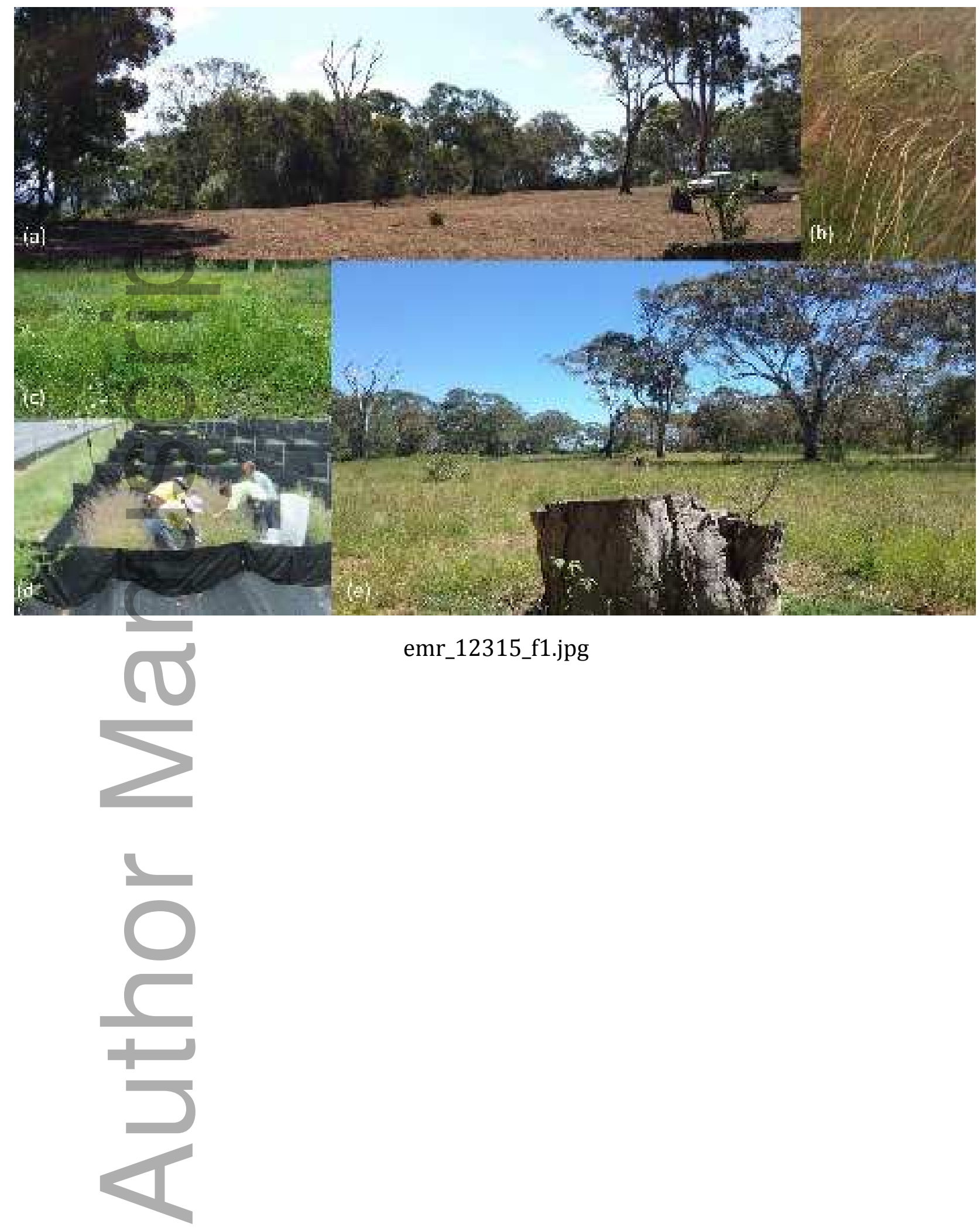

This article is protected by copyright. All rights reserved 


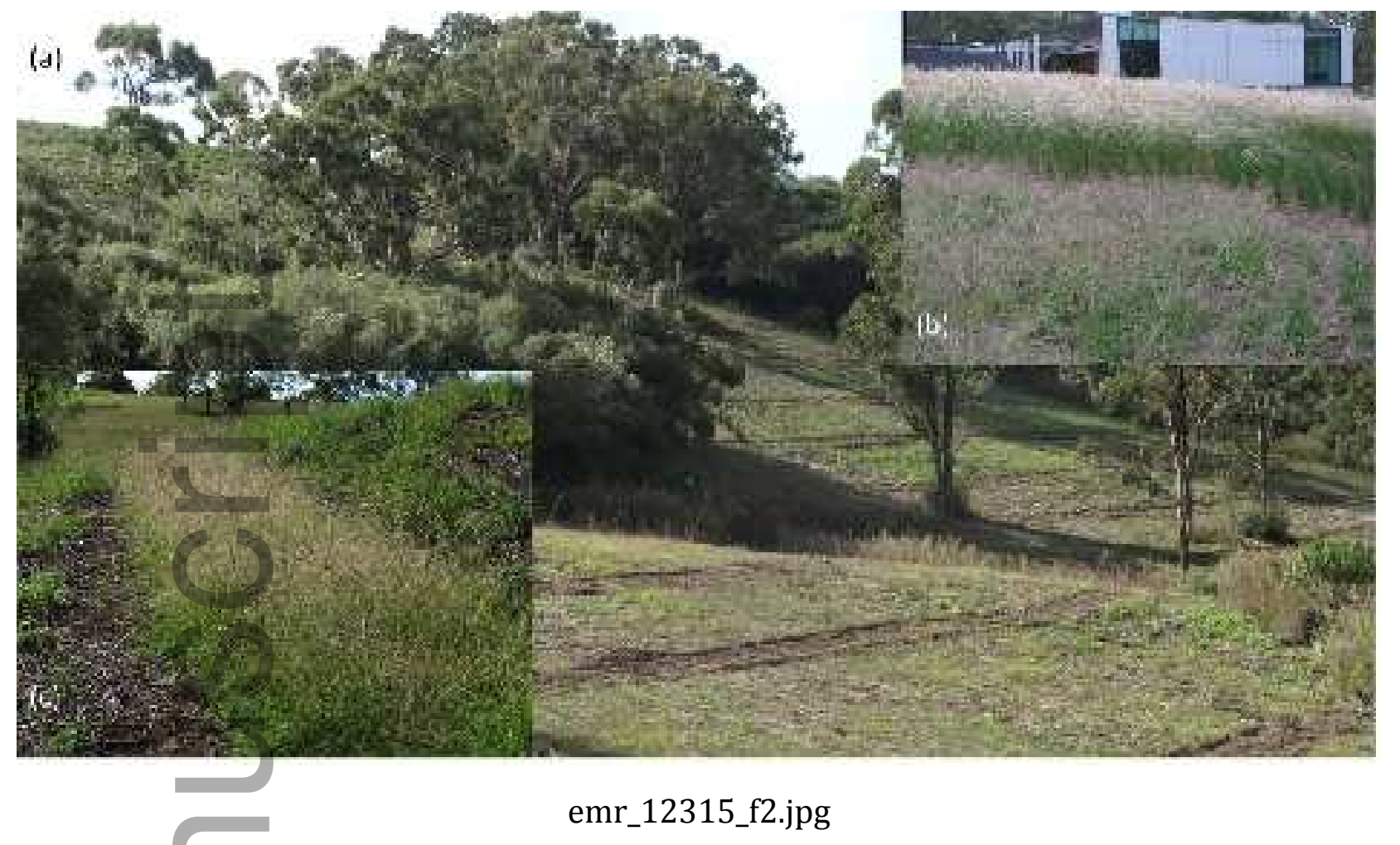

12_.jpg

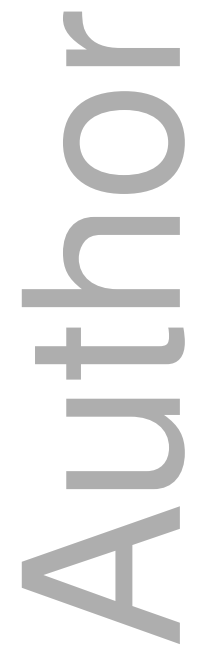

This article is protected by copyright. All rights reserved 

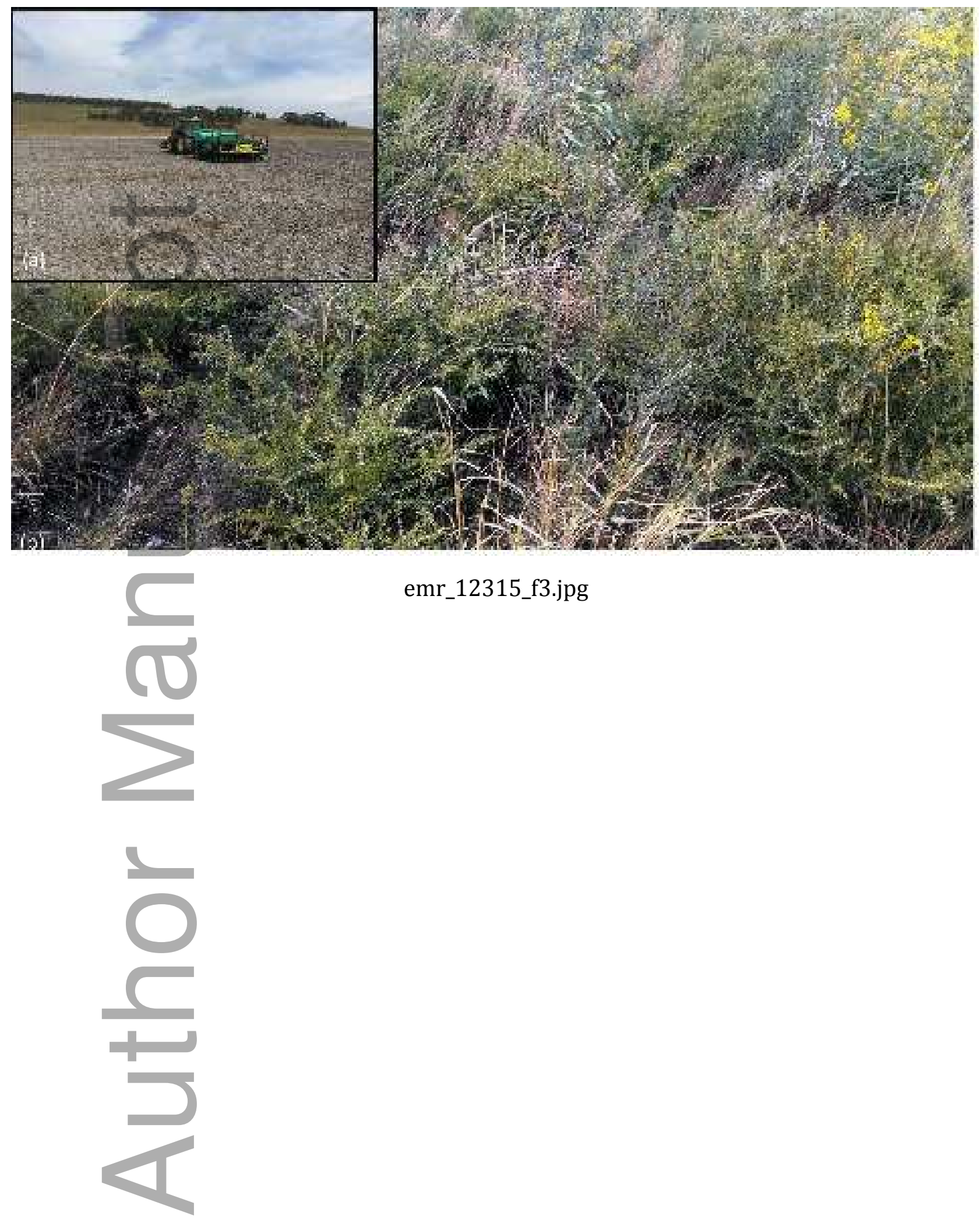

emr_12315_f3.jpg 

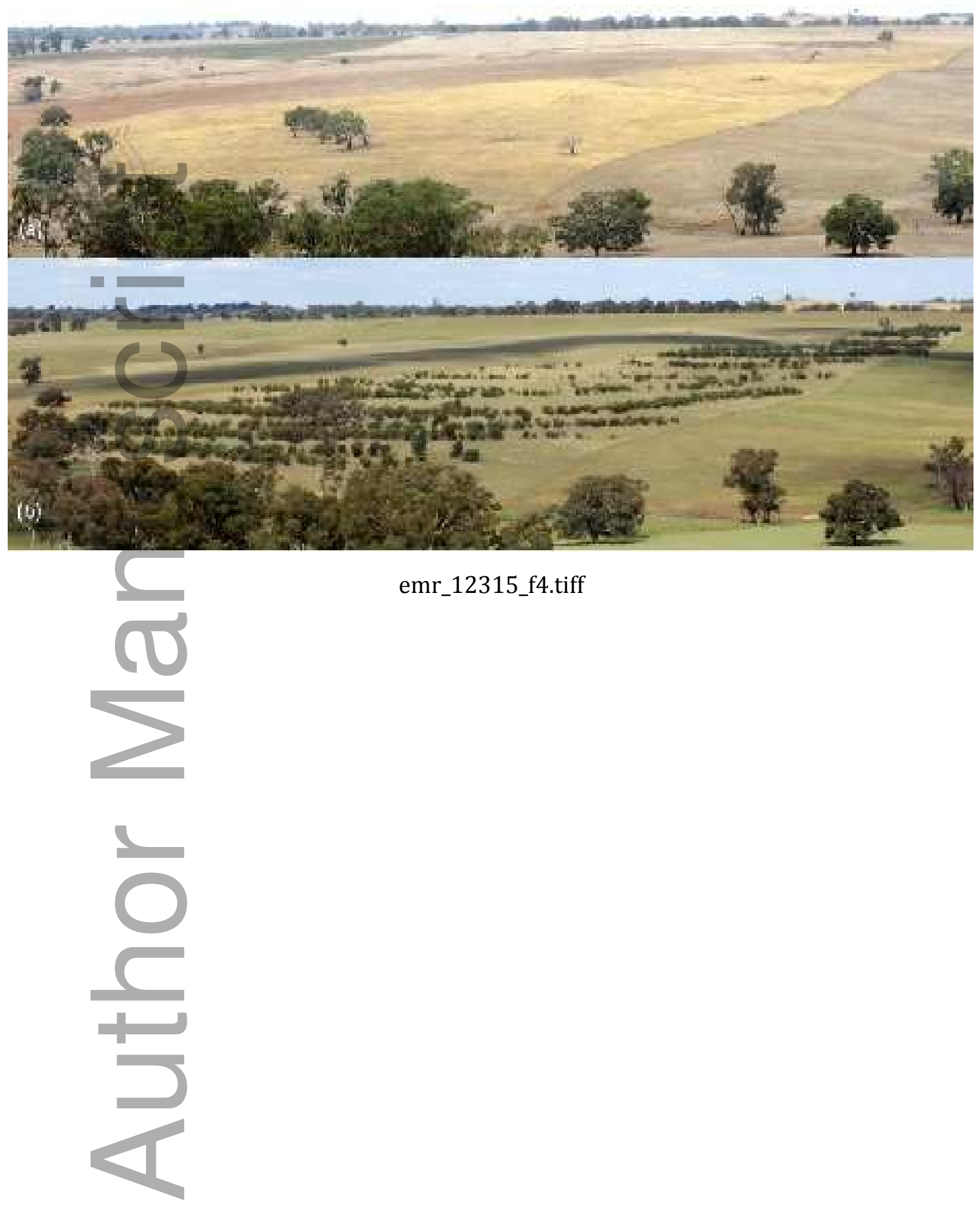

emr_12315_f4.tiff 


\section{University Library}

\section{- M M N E R VA A gateway to Melbourne's research publications}

Minerva Access is the Institutional Repository of The University of Melbourne

Author/s:

Cuneo, P;Gibson-Roy, P;Fifield, G;Broadhurst, L;Berryman, T;Crawford, A;Freudenberger, D

Title:

Restoring grassy woodland diversity through direct seeding: Insights from six "best-practice' case studies in southern Australia

Date:

2018-05-01

Citation:

Cuneo, P., Gibson-Roy, P., Fifield, G., Broadhurst, L., Berryman, T., Crawford, A. \& Freudenberger, D. (2018). Restoring grassy woodland diversity through direct seeding: Insights from six "best-practice' case studies in southern Australia. ECOLOGICAL MANAGEMENT \& RESTORATION, 19 (2), pp.124-135. https://doi.org/10.1111/emr.12315.

Persistent Link:

http://hdl.handle.net/11343/284051 